\title{
A UNANIMIDADE NAS VOTAÇÕES NA UNIÃO EUROPEIA: DESAFIOS E
} PERSPECTIVAS NA MATÉRIA TRIBUTÁRIA

\author{
Jaqueline de Paula Leite Zanetoni* \\ Maria de Fátima Ribeiro**
}

\begin{abstract}
RESUMO:
Este estudo visou verificar se a votação por unanimidade em matéria tributária na EU deve ser abandonada. Após a contextualização, os fundamentos legais para a harmonização tributária foram colocados face aos problemas relacionados à exigência de unanimidade. Discutiu-se o papel exercido pelo TJUE e apresentou-se a proposta da Comissão. Concluiu-se que é necessária uma transição gradual para a votação por maioria qualificada em matéria tributária para tutelar interesses da EU e promover o mercado interno. $O$ trabalho foi realizado utilizando o método empírico-dialético, com ferramentas de pesquisa bibliográfica e como sistema de referência Construtivismo Lógico-Semântico acoplado a Law and Economics.
\end{abstract}

Palavras chave: Direito Internacional. Direito Tributário Internacional. Tratados Internacionais. Unanimidade. União Europeia.

\section{THE UNANIMITY REQUIREMENT IN THE EUROPEAN UNION: CHALLENGES AND PROSPECTS IN TAX LEGISLATION}

\begin{abstract}
:
This paper aimed to verify whether the unanimous vote on tax matters in the EU should be abandoned. Following the contextualization, legal foundations for tax harmonization were placed alongside problems related to the requirement of unanimity. ECJ's role in tax policies was discussed and the solution proposed by EC was presented. It was concluded that it is necessary to gradually transition to qualified majority voting in tax matters ensuring the interests of EU and promoting the internal market. This paper was used empirical-dialectical method through bibliographic research tools and having as reference systems semantic-logical constructivism coupled with Law and Economics.
\end{abstract}

\footnotetext{
* Possui graduação em Direito pela Faculdade de Direito de São Bernardo do Campo (2011). Especialista em Direito Tributário pela Pontifícia Universidade Católica de São Paulo (PUC-SP). Master of Laws with honors, L.L.M International Tax Law pela WU Vienna University of Economics and Business. Mestranda em Direito pela Universidade de Marília (UNIMAR). Professora de Direito da Universidade de Mogi das Cruzes (Campus Vila Leopoldina/SP). Membro do corpo diretor da FEPODI (2019/2022). Advogada. Tem experiência na área de Direito, com ênfase em Direito Tributário Internacional (jaquelineplzanetoni@ gmail.com)

** Possui graduação em Direito pela Universidade Estadual de Londrina, Mestrado em Ciências Jurídicas Empresarias pela Pontifícia Universidade Católica do Rio de Janeiro, Doutorado em Direito pela Pontifícia Universidade Católica de São Paulo, Pós Doutorado em Direito Fiscal/Tributário na Universidade de Lisboa. Curso complementar créditos de Doutorado na Sapienza Università di Roma Facoltà di Economia e Facoltà di Giurisprudenza) Roma Itália. É professora titular do Programa de Mestrado e Doutorado em Direito e do curdo de graduação em direito da Universidade de Marília (UNIMAR) desde 2002. Integra a Diretoria do Instituto de Direito Tributário de Londrina. Professora convidada da Universidade Estadual de Londrina. Tem experiência na área de Direito, com ênfase em Direito Tributário, atuando principalmente nos seguintes temas: direito tributário, tributação e desenvolvimento econômico e social, políticas públicas, princípios constitucionais e soberania, extrafiscalidade, direito constitucional e internacional econômico (professoramariadefatimaribeiro@gmail.com)
} 
Key words: International Law. International Tax Law. International Treaties. Unanimity. European Union.

\section{INTRODUÇÃO}

O quadro institucional da União Europeia não atua de forma eficiente eis que não acompanha a rapidez do mercado atual ao exigir votação unânime entre os vinte e oito Estados-Membros para à adoção de quaisquer medidas internas em matéria tributária, o que ocorre desde 1958, possuindo o Parlamento Europeu um papel meramente consultivo (EUROPEAN COMISSION, 2019, p. 2).

Paralelamente, em uma era de fronteiras abertas com uma economia globalizada e digital, algumas empresas multinacionais conduziram com sucesso suas estratégias de planejamento tributário através da exploração de lacunas e incompatibilidades nas regras tributárias internacionais. ${ }^{1}$

Nesse sentido, a pressão política realizada por empresas multinacionais reflete tanto no processo decisório como nas alterações em matéria tributária efetuadas junto à União Europeia, resultando assim, em políticas tributárias de interesse particular de determinados Estados-Membros e não da Comunidade Europeia como um todo.

Em outras palavras, através do procedimento de votação unanime, a União Europeia vem permitindo que os Estados-Membros construam modelos de negócio em torno do conceito de um sistema fiscal concebido para atrair determinadas atividades ou consumidores alvo.

Sob o ponto de vista prático, ressalta-se que, o progresso em políticas tributárias junto à União Europeia nos últimos anos fora resultado de pressão pública e desde 2003 observa-se uma falta de produção de legislação tributária (ou decisões coerentes por parte do Tribunal de Justiça da União Europeia) que promova uma maior harmonização fiscal.

Corroborando com o entendimento aqui exposto, $75 \%^{2}$ (setenta e cinco por cento) dos cidadãos europeus demandam maiores ações da União Europeia a fim de combater

\footnotetext{
${ }^{1}$ Para mais informações, ver: AVI-YONAH, Reuven S./XY, Haiyan. Global taxation after the crisis: Why BEPS and MAATM are inadequate responses, and what can be done about it? University of Michigan Public Law Research Paper n. 494, 2016, p. 4.

${ }^{2}$ Disponível em: https://www.europarl.europa.eu/news/en/headlines/economy/20160707STO36204/tax-fraud75-of-europeans-want-eu-to-do-more-to-fight-it (acesso 28 de abril de 2019).
} 
práticas elisão e evasão fiscal ${ }^{3}$. Portanto, faz-se necessário que as demandas sociais sejam respondidas de forma rápida e eficaz, devendo ser investigado se a atual necessidade de unanimidade seria um entrave para a mudança requerida.

Simultaneamente, como justificativa abstrata, a soberania tem sido utilizada pelos Estados-Membros como base para a proteção dos interesses nacionais específicos em detrimento do mercado interno europeu ao longo dos anos (EUROPEAN COMISSION, 2019, p. 6).

Dessa forma, a partir desta pesquisa, objetiva-se demonstrar que a necessidade de unanimidade para resolver questões legais sobre a política tributária seguida pela União Europeia não apresenta resultados favoráveis na conjuntura atual - especialmente - sob o ponto de vista de uma economia globalizada e digital.

É dizer, um número significativo de propostas sobre questões tributárias consideradas importantes dentro do conceito de mercado interno promovido pela União Europeia encontra-se estagnado eis que os Estados-Membros não atingem a unanimidade exigida.

À vista disso, através do Construtivismo Lógico-Semântico, o item 2 abordará os fundamentos legais para a harmonização em matéria tributária nos tratados da União Europeia.

$\mathrm{O}$ item 3 tem como propósito abordar os problemas relacionados à exigência de votação unanime em matéria tributária na União Europeia utilizando-se de pesquisa bibliográficas e como sistema de referência o Law and Economics. Já o item 4, ainda que de forma breve, fará uma análise do papel legislativo exercido pelo Tribunal de Justiça da União Europeia (European Court of Justice - "ECJ") - ainda que de forma indireta - em matérias tributárias perante a União Europeia.

Através do item 5 pretende-se expor de forma clara à solução proposta pela Comissão Europeia em janeiro de 2019, no que tange a adoção do sistema de maioria qualificada em matéria tributária na União Europeia. Fato é que, as questões relacionadas à matéria tributária constituem uma das poucas áreas políticas nas quais as decisões ainda devem ser adotadas por meio de um processo legislativo especial (votação unânime).

\footnotetext{
${ }^{3}$ Para os conceitos de elusão e evasão fiscal ver: TORRES, Heleno Taveira. Direito tributário e direito privado. Autonomia privada, simulação e elusão tributária. São Paulo: RT, 2000.
} 
Como se assim não o fosse, o Brexit juntamente com o crescimento dos movimentos nacionalistas nos países europeus torna o cenário delicado para qualquer (eventual) mudança, principalmente no que tange ao aqui exposto.

Dessa forma, a fim de proteger uma vantagem competitiva em áreas específicas, o progresso é por vezes bloqueado a fim de atender ao interesse de um único Estado-Membro da União Europeia.

Assim, poder-se-ia questionar se a exigência de unanimidade nas votações em matéria tributária (ainda) atende aos objetivos de uma União concedida com o fim de promover o mercado interno e a livre-concorrência e até que ponto a soberania de um único Estado-Membro continuará bloqueando iniciativas exigidas pelos outros vinte e sete EstadosMembros.

Por fim, para atingir os objetivos traçados nesse artigo, o método aplicável é o empírico-dialético e o sistema de referência utilizado é formado da conjugação entre o Construtivismo Lógico-Semântico de Barros Carvalho ${ }^{4}$ e ferramentas específicas do Law and Economics ${ }^{5}$, estando, obviamente, mais presente a última destas no presente artigo.

\section{FUNDAMENTOS NORMATIVOS DA HARMONIZAÇÃO TRIBUTÁRIA NOS TRATADOS DA UNIÃO EUROPEIA}

Inicialmente, faz-se necessário mencionar que, o tratado objeto do presente estudo materializa-se em um acordo vinculativo entre Estados-Membros da União Europeia, cujo escopo definiu os objetivos e regras para a sua instituição, bem como dispõe a forma pela qual as decisões serão tomadas dentro da própria União Europeia e a relação desta com os Estados-Membros.

Nesse ponto, ressalta-se que, deixar-se-ão de lado as propostas clássicas do estudo da harmonização internacional ${ }^{6}$, pois o que se quer reforçar é o fato de que o sistema teórico

\footnotetext{
${ }^{4}$ Ver CARVALHO, Paulo de Barros. Direito Tributário: linguagem e método. $2^{\mathrm{a}}$ edição. São Paulo: Noeses, 2008.

${ }^{5}$ Para mais informações: ZYLBERSZTAJN, Décio; STAJN, Rachel. Direito e economia: análise econômica do direito e das organizações. Rio de Janeiro: Campus jurídico, 2005. Ed. Quartier Latin, 2005.

${ }^{6}$ Como importantes textos clássicos a respeito do tema, entre outros: CASELLA, Paulo Borba. Modalidades de harmonização, unificação e uniformização do Direito- O Brasil e as convenções interamericanas de direito internacional privado. In: INTEGRAÇÃo JURÍDICA INTERAMERICANA: As convenções interamericanas do direito internacional privado (CIDIP's) e o direito brasileiro. São Paulo: Ltr, 1998; CASELLA, Paulo Borba. Harmonização do direito internacional interamericano. Disponível em: http://www.cacb.org.br/mediacao_arbitragem/artigos/Harmonizacao\%20do\%20Direito\%20Internacional\%20Int
} 
apresentado perfaz, especialmente em suas facetas da Teoria da Linguagem, uma interessante plataforma para a abordagem do tema proposto.

Movendo-se mais adiante e especificamente, todas as medidas adotadas pela União Europeia deverão ser fundamentadas nos tratados que foram aprovados voluntariamente e democraticamente por todos os Estados-Membros.

Particularmente, a semântica do artigo 113 do Tratado sobre o Funcionamento da União Europeia (Treaty on the Functioning of the European Union - "TFEU") dispõe acerca da harmonização das disposições legislativas e administrativas com foco predominantemente nos impostos sobre bens e serviços (impostos indiretos, tais como: imposto sobre valor agregado e impostos especiais de consumo), a fim de assegurar o estabelecimento e o funcionamento do mercado interno e impedir eventuais distorções de concorrência.

O Conselho, deliberando por unanimidade, de acordo com um processo legislativo especial, e após consulta do Parlamento Europeu e do Comité Económico e Social, adota as disposições relacionadas com a harmonização das legislações relativas aos impostos sobre o volume de negócios, aos impostos especiais de consumo e a outros impostos indiretos, na medida em que essa harmonização seja necessária para assegurar o estabelecimento e o funcionamento do mercado interno e para evitar as distorções de concorrência. (EUROPEAN UNION, 2012, Art. 113)

Ainda no que tange as disposições legislativas e administrativas com foco predominantemente nos demais impostos, o artigo 115 do Tratado sobre o Funcionamento da União Europeia prevê a aproximação das disposições legislativas, regulamentares ou administrativas dos Estados-Membros.

Sem prejuízo do disposto no artigo 114.o, o Conselho, deliberando por unanimidade, de acordo com um processo legislativo especial, e após consulta do Parlamento Europeu e do Comité Económico e Social, adota diretivas para a aproximação das disposições legislativas, regulamentares e administrativas dos Estados-Membros que tenham incidência direta no estabelecimento ou no funcionamento do mercado. (EUROPEAN UNION, 2012, Art. 113)

Assim, através de uma análise normativa (no plano do S4 pretendido pelo Construtivismo Lógico-Semântico), conclui-se que, nos termos dos artigos aqui analisados,

eramericano.doc. Acesso em: 04/06/2013; OLIVEIRA, Renata Fialho. Harmonização jurídica no direito internacional. São Paulo: Quartier Latin, 2008; VIEGAS, Vera Lúcia. Teoria da harmonização jurídica: alguns esclarecimentos. In: Novos Estudos Jurídicos. Vol. 9, n. 3. Itajaí: UNIVALI, 2004; MELLO, Celso Duvivier de Albuquerque. Curso de direito internacional público. Vol. I e II. 12a Ed. Rio de Janeiro: Renovar, 2000. 
como regra geral, o Conselho deve concordar por unanimidade ${ }^{7}$ sobre as propostas fiscais apresentadas no domínio da tributação junto à União Europeia.

Todavia, independentemente da necessidade de revisão dos dispositivos legais transcritos acima, um tratado adicional da União Europeia contém igualmente outro dispositivo que confere flexibilidade à utilização de outros procedimentos (que não a unanimidade), o que será abordado no item 4 do presente artigo.

\section{A EXIGÊNCIA DE UNANIMIDADE NAS VOTAÇÕES EM MATÉRIA TRIBUTÁRIA NA UNIÃo EUROPEIA}

Dessa forma, ante à exigência da adoção de legislação harmonizada na União Europeia, todo e qualquer ato em matéria tributária demanda à aceitação unânime dos Estados-Membros.

Ocorre que, a unanimidade exigida na União Europeia, por diversas vezes, não é alcançada ou acaba por conduzir a políticas tributárias abaixo do ideal demandado para combater certas práticas consideradas abusivas e/ou para abranger novas formas de tributação em razão das atuais demandas sociais (EUROPEAN COMISSION, 2019, p. 8).

Sob o ponto de vista prático, a necessidade de votação unânime na tomada de decisões acaba por dificultar o progresso econômico de certos Estados-Membros, bem como possui papel limitador ao potencial das políticas tributárias dentro da União Europeia destinadas à solução de transações transfronteiriças.

Corroborando com o entendimento aqui exposto, um número significativo de propostas sobre questões em matéria tributária consideradas importantes dentro do contexto do mercado único promovido internamente pela União Europeia encontra-se estagnado, eis que os Estados-Membros não conseguem atingir a unanimidade exigida. ${ }^{8}$

Como se assim não o fosse, o progresso em políticas tributárias junto à União Europeia nos últimos anos foram o resultado de pressão pública e desde 2003 observa-se uma falta de produção de legislação tributária (ou decisões coerentes por parte do Tribunal de Justiça da União Europeia) que promova uma maior harmonização fiscal.

\footnotetext{
${ }^{7} \mathrm{O}$ termo 'unanimidade' relaciona-se com a necessidade de todos os países da União Europeia, quando reunidos no Conselho para a acordo antes de uma proposta poder ser adotada. European Union, Glossary of summaries. Disponível em: https://eur-lex.europa.eu/summary/glossary/unanimity.html (acesso em 28 de abril de 2019).
} 
Inúmeros obstáculos à tomada de decisão por unanimidade em matéria fiscal vêm sendo relatados e, assim, os principais serão aqui analisados sob a perspectiva do sistema de referência ora adotado (Law and Economics). Pois bem.

Inicialmente, às deliberações em matéria tributária dentro da União Europeia costumam prolongar-se durante anos e por vezes são abandonas sem qualquer decisão final, haja vista que, a oposição de um único Estado-Membro é suficiente para impedir a finalização do acordo, sendo um clássico dilema da Teoria dos Jogos. ${ }^{9}$

O atual sistema de votação unânime, em verdade, acaba por conceder uma quantidade generosa de poder para um único Estado-Membro, eis que o mesmo é livre para simplesmente vetar qualquer medida que seja contrária ao seu interesse particular, podendo abster-se de negociar seriamente a medida em pauta ou de apresentar soluções alternativas para a mesma.

De acordo com a própria Comissão Europeia, inúmeras propostas em matéria tributária são bloqueadas no Conselho sem qualquer discussão prévia, criando uma quase forma de falha de mercado, dando poderes desmensurados a um agente econômico (o que é claramente uma externalidade negativa na balança de poderes da União Europeia). ${ }^{10}$

Ademais, em consequência ao poder de veto, os Estados-Membros acabam por utilizar-se de propostas em matéria tributária como moeda de troca para outras demandas de seu interesse (EUROPEAN COMISSION, 2019, p. 8), potencializando a assimetria de informações no campo das relações internacionais, (quase) (con)formando uma outra falha de mercado.

Não obstante, quando a unanimidade é alcançada a decisão final - por diversas vezes - perdeu a sua finalidade em razão do tempo dispendido durante as discussões prévias, dificultando à sua aplicação prática e limitando o seu impacto positivo junto à sociedade.

Além disso, as decisões tomadas por unanimidade somente poderão ser revertidas ou alteradas por unanimidade - o que gera um círculo vicioso - eis que os Estados-Membros se tornam excessivamente cautelosos diante da necessidade real de uma mudança nos dispositivos vigentes (EUROPEAN COMISSION, 2019, p. 8).

\footnotetext{
${ }^{8}$ Por exemplo, as propostas da Comissão Europeia para o CCCTB e para um regime definitivo de IVA na União Europeia encontram-se estagnadas neste momento.

${ }^{9}$ Para mais informações sobre a Teoria dos jogos no campo da ciência política: MORROW, James. Game Theory for Political Scientists. Princeton, NJ: Princeton University Press, 1994.
} 
Portanto, não nos parece adequado que, às políticas tributárias adotadas pela União Europeia permaneçam amarradas a uma regra de unanimidade, a qual é mal utilizada (sobretudo) em razão de interesses puramente nacionais em detrimento da própria União como um todo.

\section{O TRIbUNAL DE JUSTiÇA E A POLÍtica TRIBUtária NA UNião EUROPEIA}

Nos últimos anos, a União Europeia tem acolhido e permitindo a criação de paraísos fiscais dentro de suas fronteiras ao admitir à criação de regimes e sistemas especiais, bem como ao não condenar de forma adequada tais condutas.

Sob o ponto de vista prático, instituiu-se um ambiente real para a realização e crescimento de práticas fiscais nocivas dentro do território da União Europeia.

Apesar da posição adotada pela União Europeia e da postura assumida pela própria Organização para a Cooperação e Desenvolvimento Econômico (OCDE), muitos regimes e incentivos são favoráveis para empresas (intra) europeias e grupos multinacionais para evitar legalmente (ou adiar) impostos, tais como: IP box, decisões fiscais (ou seja, APA - Advanced Pricing Agreements), transparência ou opacidade de empresas e à transferência legal de rendimentos (em alguns casos, inclusive, a possibilidade de exportar a nacionalidade de uma empresa).

Eventualmente, todo o aqui disposto pode ser atribuído as instituições legislativas da própria União Europeia, eis que são silentes no que tange às questões de fraude tributária e elisão/evasão fiscal. Resultando, assim, em uma inaptidão para combater tais práticas ante o procedimento ineficiente de votação adotado em matéria tributária.

A fim de atenuar o cenário atual, a Comissão Europeia acaba por utilizar-se - de forma recorrente - das decisões proferidas pelo Tribunal de Justiça da União Europeia em matéria tributária a fim de evitar deliberações nas diretivas em foco eis que já são esperadas decisões não-consensuais entre os Estados-Membros.

\footnotetext{
${ }^{10}$ Para mais sobre externalidades e Teoria dos Jogos: FEREJOHN, John; PASQUINO, Pasquale. The Rational Choice Theory in the political science: concepts of rationality on political theories. Revista brasileira das Ciências Sociais, vol.16, n.45, p.05-24, feb. 2001.
} 
Como resultado, o chamado soft law assumiu um papel de liderança no seio da União Europeia com a redução da utilização da fonte tradicional hard law. ${ }^{11}$

Ocorre que, o Tribunal de Justiça da União Europeia - reiteradamente - não condena de forma adequada os regimes tributários dos Estados-Membros que levaram a chamada corrida para o fundo (race to the bottom) para o interior da União Europeia (o que acaba por agravas à situação descrita inicialmente no presente item).

\section{A PROPOSTA APRESENTAdA PELA COMissão EUROPEIA: UMA ANÁliSE CRÍTICA}

\subsection{A Comunicação da Comissão da União Europeia e o espaço normativo para a mudança}

Em janeiro de 2019, a Comissão Europeia iniciou o debate sobre a necessidade de reformar a tomada de decisões em matéria tributária junto à União Europeia ao propor uma transição gradual (em quatro etapas) para a votação por maioria qualificada no âmbito do processo legislativo ordinário.

Para tanto, fora publicada uma Comunicação pela Comissão Europeia endereçada ao Parlamento Europeu, ao Conselho Europeu e ao Conselho com o objetivo de consolidar a reputação da União Europeia como líder global no que tange a habilidade de encontrar soluções modernas e realistas para uma política tributária no século XXI.

Neste ponto, faz-se necessário aludir que, uma votação por maioria qualificada é alcançada no âmbito da União Europeia se duas condições forem observadas, são elas: 55\% (cinquenta e cinco por cento) dos países da União Europeia votarem a favor e a proposta é apoiada por países que representam pelo menos 65\% (sessenta e cinco por cento) da população total da União Europeia. ${ }^{12}$

Ainda, de acordo com à Comunicação publicada pela Comissão Europeia (EUROPEAN COMISSION, 2019, p. 9), um tratado adicional da União Europeia contém as

\footnotetext{
${ }^{11}$ Para mais informações: Lampreave, P. (2012). Fiscal Competitiveness versus Harmful Tax Competition in the European Union.Bulleting for International Taxation, 65(6).

Para mais informações: https://www.consilium.europa.eu/pt/council-eu/voting-system/qualified-majority/ (acesso 29 de abril de 2019).
} 
disposições necessárias para fundamentar à mudança na tomada de decisões de unanimidade para maioria qualificada no Conselho, as chamadas clauseles-passarelles. ${ }^{13}$

Corroborando com o entendimento aqui exposto, nos termos do artigo 48, parágrafo 7, do Tratado da União Europeia (Treaty on European Union - "TEU"), por exemplo, resta autorizado aos Estados-Membros adotarem a votação por maioria qualificada ou adorarem o processo legislativo ordinário (com o Parlamento Europeu no processo de tomada de decisão) em áreas normalmente sujeitas por unanimidade, incluindo matéria tributária, veja-se:

\begin{abstract}
Quando o Tratado sobre o Funcionamento da União Europeia ou o Título V do presente Tratado determine que o Conselho delibera por unanimidade num determinado domínio ou num determinado caso, o Conselho Europeu pode adotar uma decisão que autorize o Conselho a deliberar por maioria qualificada nesse domínio ou nesse caso. O presente parágrafo não se aplica às decisões que tenham implicações no domínio militar ou da defesa.

Quando o Tratado sobre o Funcionamento da União Europeia determine que o Conselho adota atos legislativos de acordo com um processo legislativo especial, o Conselho Europeu pode adotar uma decisão autorizando a adoção dos referidos atos de acordo com o processo legislativo ordinário.

As iniciativas tomadas pelo Conselho Europeu com base no primeiro ou no segundo parágrafo são comunicadas aos Parlamentos nacionais. Em caso de oposição de um Parlamento nacional notificada no prazo de seis meses após a comunicação, não é adotada a decisão a que se referem o primeiro ou o segundo parágrafo. Se não houver oposição, o Conselho Europeu pode adotar a referida decisão.

Para a adoção das decisões a que se referem o primeiro ou o segundo parágrafo, o Conselho Europeu delibera por unanimidade, após aprovação do Parlamento Europeu, que se pronuncia por maioria dos membros que o compõem. (EUROPEAN UNION, 1992, Art. 48(7)).
\end{abstract}

Assim, para ativar as chamadas clauseles-passarelle, o Conselho Europeu deve tomar uma decisão unânime com o consentimento do Parlamento Europeu e sem objeções dos parlamentos nacionais - o que poderia ser um entrave para a sua aplicação em razão dos problemas já levantados no item 3 do presente trabalho.

Não obstante, ao defender a transição para a votação por maioria qualificada na tomada de decisões em matéria tributária na União Europeia, a Comissão defendeu que a mesma deverá ser realizada com o papel ativo do Parlamento Europeu como já se observa em outras áreas de interesse político da própria União Europeia (EUROPEAN COMISSION, 2019, p. 8).

\footnotetext{
${ }^{13}$ Para mais informações: A Union that Delivers Making Use of the Lisbon Treaty's Passerelle Clauses. European Political Strategy Center, 14 January 2019. Disponível em: https://ec.europa.eu/epsc/sites/epsc/files/epsc_brief_passerelles_2.pdf (acesso 29 de abril de 2019).
} 
A partir da concepção que o Parlamente Europeu não é vinculado por pressões e interesses nacionais eis que é diretamente eleito, o mesmo poderia fornecer novas ideias nas negociações com vistas a refletir os interesses da União Europeia como um todo.

Nesse sentindo, somente com a concessão de um papel decisório ao Parlamento Europeu no processo legislativo em políticas tributárias é que seria possível tornar o processo de tomada de decisão o mais democrático dentro da estrutura adotada pela União Europeia.

Fato é que, nos últimos anos, o papel exercido pelo Parlamento Europeu junto às políticas tributárias adotadas na União Europeia produziu impactos significativos principalmente - no que tange à solução dos grandes escândalos tributários que foram noticiados pela mídia. Em outras palavras, através dos comitês ad hoc, o Parlamento Europeu vem promovendo uma agenda audaciosa no que tange as medidas para uma justa tributação.

\subsection{As etapas propostas pela Comissão da União Europeia para a quebra da unanimidade}

Movendo-se adiante e mais especificamente, de acordo com a transição gradual proposta pela Comissão Europeia, a votação por maioria qualificada seria direcionada na primeira etapa às medidas que melhorem a cooperação e assistência mútua na luta contra a fraude tributária e elisão/evasão fiscal., não tendo impacto direto no poder de tributar dos Estados-Membros (EUROPEAN COMISSION, 2019, p. 11).

Além disso, a primeira etapa abrangeria a conclusão de acordos internacionais entre a União Europeia e terceiros países no que tange às medidas descritas no parágrafo anterior (EUROPEAN COMISSION, 2019, p. 11), incluindo iniciativas de combate ao abuso de tratado que os Estados-Membros já concordaram em nível internacional e as discutidas no contexto do projeto BEPS (base erosion and profit shifting). ${ }^{14}$

Dessa forma, o passo inicial para a implementação da primeira etapa seria manifestado através da facilitação do cumprimento das obrigações tributárias das empresas no mercado único com à apresentação de relatórios harmonizados, resultando em um processo mais rápido e eficiente para concordar com questões amplamente consensuais. ${ }^{15}$

\footnotetext{
${ }^{14}$ Para mais informações do projeto BEPS e iniciativas de combate ao abuso de tratado: ZANETONI, Jaqueline de Paula Leite Zanetoni. The Third State PE Rule in Article 29 In: Special Features of the UN Model Convention.1 ed.Viena: Linde, 2019, v.1, p. 589-614.

${ }^{15}$ EUROPEAN COMMISION, 2019. Towards a more efficient and democratic decision making in EU tax policy, 15th January 2019 COM 2019(8) final. Disponível em:
} 
Na segunda etapa, a votação por maioria qualificada deverá ser introduzida como uma ferramenta útil para o progresso de medidas em que a tributação suporta outros objetivos políticos (EUROPEAN COMISSION, 2019, p. 11).

Sob o ponto de vista prático, espera-se que a tomada de decisões seja realizada de forma mais eficiente em relação aos impostos de outras áreas de interesse público a fim de implantar uma politica energética ecológica junto à União Europeia, bem como afim de apoiar objetivos da própria União no que tange as mudanças climáticas (por exemplo: na luta contra mudanças climáticas, proteção ao meio ambiente, melhoria da politica de saúde pública e de transporte). ${ }^{16}$

Não obstante, na terceira etapa, o uso da votação por maioria qualificada visa auxiliar na modernização das regras tributárias já harmonizados na União Europeia, tais como os de Imposto sobre o Valor Adicionado (IVA) e impostos especiais de consumo (EUROPEAN COMISSION, 2019, p. 12).

Para a Comissão Europeia (EUROPEAN COMISSION, 2019, p. 12), uma tomada de decisão de forma rápida em tais áreas permitiria aos Estados-Membros acompanhar os mais recentes desenvolvimentos tecnológicos e as mudanças no mercado. Neste ponto, ressalta-se que, a Comissão Europeia, defende a criação de um Imposto sobre o Valor Adicionado sustentável que seja à prova de fraude e favorável às empresas.

Finalmente, na quarta etapa, o uso da votação por maioria qualificada seria introduzido em outras iniciativas na área tributária a fim de promover o mercado interno, bem como resguardar os interesses dos Estados-Membros através de uma tributação juta e competitiva na Europa (EUROPEAN COMISSION, 2019, p. 12).

Nesse sentido, a votação por maioria qualificada, seria essencial para a progresso de alguns projetos em matéria tributária destacados pela Comissão Europeia como de suma importância no cenário atual a fim de contribuir para um mercado interno, são eles: Common

https://ec.europa.eu/taxation_customs/sites/taxation/files/15_01_2019_communication_towards_a_more_efficie nt_democratic_decision_making_eu_tax_policy_en.pdf (acesso 28 de abril 2019).

${ }^{16}$ EUROPEAN COMMISION, 2019. Towards a more efficient and democratic decision making in EU tax policy, 15th January 2019 COM 2019(8) final. Disponível em: https://ec.europa.eu/taxation_customs/sites/taxation/files/15_01_2019_communication_towards_a_more_efficie nt_democratic_decision_making_eu_tax_policy_en.pdf (acesso 28 de abril 2019). 
Consolidated Corporate Tax Base (CCCTB) ${ }^{17}$ e a criação de um novo sistema para o tributação da economia digital.

Para tanto, foi sugerido pela comunicação publicada pela Comissão Europeia que os Estados-Membros decidam rapidamente convergir para a decisão de desenvolver as duas primeiras etapas e decidam convergir para as duas últimas etapas até o final de 2025.

\section{CONCLUSÃO}

A votação por maioria qualificada tem produzido resultados claros em outras áreas dentro da União Europeia, inclusive para áreas que são tão politicamente sensíveis como a tributação.

Um número significativo de propostas sobre questões em matéria tributária consideradas importantes no contexto do mercado interno (e da União Europeia como um todo) estão estagnadas porque os Estados-Membros não são capazes de alcançar a unanimidade exigida.

A Economia atual possui vários modelos de negócios que precisam ser estudados e acobertados pelos tratados internacionais a fim de determinar a tributabilidade dos mesmos e, caso seja possível, determinar o sujeito competente para tanto, devendo os dispositivos legais sobre o tema acompanhar a velocidade de tais mudanças a fim de atender aos anseios da sociedade.

Não há que se falar em desrespeito a soberania dos Estados-Membros, eis que estes através de um ato de vontade decidiram por adentrar na União Europeia a fim de se beneficiar dos incentivos financeiros e econômicos desta e, portanto, devem estar sujeitos a uma política de concorrência livre e ao seu mercado interno.

A proposta atual é vista como desfavorável para os Estados-Membros considerados menores em razão da exigência de unanimidade ser percebida como uma oportunidade para que estes possam perseguir seus próprios interesses na política externa no plano da União Europeia.

O apoio dos Estados-Membros para a votação por maioria qualificada no campo tributário vai depender da proteção dos seus interesses econômicos, bem como da segurança

\footnotetext{
${ }^{17}$ Para mais informações: VITA, Jonathan Barros. As Formas de Bases de Cálculo do Imposto Sobre a Renda na Experiência Europeia: desvendando pontos cegos de visão brasileiras. Direito Tributário Internacional homenagem ao Professor Alberto Xavier. 1ed.São Paulo: Quartier, 2016, v. 1, p. 347-364.
} 
da relação estabelecida com os demais Estados-Membros, o que não pode ser causa à criação de externalidades negativas, como o bloqueio do progresso geral do sistema.

A unanimidade deve ser progressivamente abandonada para a maioria qualificada em matéria tributária de forma a abranger tanto os impostos diretos como indiretos e suas alíquotas, a fim de evitar que o cenário atual de protagonismo do Tribunal de Justiça da União Europeia em detrimento das instituições políticas permaneça.

\section{REFERÊNCIAS}

AVI-YONAH, Reuven e XY, Haiyan. Global taxation after the crisis: Why BEPS and MAАTM are inadequate responses, and what can be done about it?, University of Michigan Public Law Research Paper n. 494, (2016).

CALIENDO, Paulo. Direito tributário e análise econômica do direito: uma visão crítica. Rio de Janeiro: Elsevier, 2008.

CASELLA, Paulo Borba. Modalidades de harmonização, unificação e uniformização do Direito- O Brasil e as convenções interamericanas de direito internacional privado. In: INTEGRAÇÃO JURÍDICA INTERAMERICANA: As convenções interamericanas do direito internacional privado (CIDIP's) e o direito brasileiro. São Paulo: Ltr, 1998.

CASELLA, Paulo Borba. Harmonização do direito internacional interamericano. Disponível em: http://www.cacb.org.br/mediacao_arbitragem/artigos/Harmonizacao\%20do\%20Direito\%20In ternacional\%20Interamericano.doc. Acesso em: 04/06/2013.

CARVALHO, Paulo de Barros. Direito Tributário: linguagem e método. $2^{a}$ edição. São Paulo: Noeses, 2008.

CARVAlHO, Cristiano Rosa de. Teoria do sistema jurídico: direito, economia, tributação. São Paulo: Ed. Quartier Latin, 2005. 
EUROPEAN COMMISION, 2019. Towards a more efficient and democratic decision making in EU tax policy, 15th January 2019 COM 2019(8) final. Disponível em:https://ec.europa.eu/taxation_customs/sites/taxation/files/15_01_2019_communication_to wards_a_more_efficient_democratic_decision_making_eu_tax_policy_en.pdf (acesso 28 de abril 2019).

EUROPEAN COMMISSION, 2019. A Union that Delivers Making Use of the Lisbon Treaty's Passerelle Clauses, European Political Strategy Center, 14 January 2019. Disponível em: https://ec.europa.eu/epsc/sites/epsc/files/epsc_brief_passerelles_2.pdf (acesso 29 de abril de 2019).

EUROPEAN UNION. Glossary of summaries. Disponível em: https://eurlex.europa.eu/summary/glossary.html\#T (acesso 29 de abril de 2019).

EUROPEAN UNION, 1992. Treaty on European Union. Disponível em: https://europa.eu/european-

union/sites/europaeu/files/docs/body/treaty_on_european_union_en.pdf (acesso 29 de abril de 2019).

EUROPEAN UNION, 2012. Treaty on the Functioning of the European Union. (consolidated version). Disponível em: https://eur-lex.europa.eu/legalcontent/EN/TXT/PDF/?uri=CELEX:12012E/TXT\&from=EN (acesso 29 de abril de 2019).

FEREJOHN, John; PASQUINO, Pasquale. The Rational Choice Theory in the political science: concepts of rationality on political theories. Revista brasileira das Ciências Sociais, vol.16, n.45, p.05-24, feb. 2001.

LAMPREAVE, P. Fiscal Competitiveness versus Harmful Tax Competition in the European Union.Bulleting for International Taxation, 65(6), (2012).

MORROW, James. Game Theory for Political Scientists. Princeton, NJ: Princeton University Press, 1994. 
OLIVEIRA, Renata Fialho. Harmonização jurídica no direito internacional. São Paulo: Quartier Latin, 2008.

POSNER, Richard A. Economic Analysis of Law. 9a ed. New York: Wolters Kluwer, 2014.

VIEGAS, Vera Lúcia. Teoria da harmonização jurídica: alguns esclarecimentos. In: Novos Estudos Jurídicos. Vol. 9, n. 3. Itajaí: UNIVALI, 2004; MELLO, Celso Duvivier de Albuquerque. Curso de direito internacional público. Vol. I e II. $12^{\mathrm{a}}$ Ed. Rio de Janeiro: Renovar, 2000.

VITA, Jonathan Barros. As Formas de Bases de Cálculo do Imposto Sobre a Renda na Experiência Europeia: desvendando pontos cegos de visão brasileiras. Direito Tributário Internacional - homenagem ao Professor Alberto Xavier. 1ed.São Paulo: Quartier, 2016, v. 1, p. $347-364$.

VITA, Jonathan Barros. Harmonização e convergência na sociedade contemporânea: entre os direitos internos e o direito internacional. In: Jorge Miranda. (Org.). Diálogo ambiental, constitucional e internacional. 1ed.Rio de Janeiro: Lumen Juris, 2015, v. 3, p. 259272.

ZANETONI, Jaqueline de Paula Leite Zanetoni. The Third State PE Rule in Article 29 In: Special Features of the UN Model Convention.1 ed.Viena: Linde, 2019, v.1, p. 589-614.

ZYLBERSZTAJN, Décio; STAJN, Rachel. Direito e economia: análise econômica do direito e das organizações. Rio de Janeiro: Campus jurídico, 2005. 